\title{
Analysis of poverty, income inequality and their effects on food insecurity in southern Ethiopia
}

Sisay Debebe ${ }^{* *}$ and Efta Hizkiel Zekarias ${ }^{2}$

\begin{abstract}
Background: Reduction of poverty and income inequality, and ensuring food security is the main goal of the Ethiopian government. In response, declines of national poverty were observed over time, but it is still a worrying concern as a significant proportion of the population remains poor. However, the trends of income inequality are rising substantially over time and thereby might exacerbate the food insecurity status in the country. This study aims to measure, identify determinants, and analyze the effects of poverty and income inequality on food insecurity status of households in Sawla town of southern Ethiopia.
\end{abstract}

Methodology: A two-stage sampling technique was used to select 227 sampled households' heads. This study applied descriptive statistics, Foster Greer Thorbecke approach, binary logistic, and quantile regression models to analyze the data.

Results: The finds of this study reveals that $34 \%$ of households are living below the poverty line with a poverty gap index of $11 \%$ and severity index of 5.6\%. The average income inequality with Gini coefficient index is found to be 0.447 . Both poverty and income inequality result is quite larger than the national average of the country. The sample households are food insecure with $20.7 \%$ depth and $13 \%$ severity indexes of food insecurity. The levels of poverty and income inequality are more worrisome among the food-insecure households. Moreover, the logistic regression model shows that levels of education, family size, being divorced, the main occupation, savings, and house ownership negatively and significantly affected the household level of poverty. Quantile regression model result shows that age, level of education, income, family size, health, savings, remittances, electric, credit, and house ownership affected households'level of income of the study area.

Conclusion: The study suggests strengthening the existing welfare-oriented strategies by undertaking intra-household resource allocations for women, encouraging participation of diversified business activities, promoting the use of family planning methods, strengthening formal education, microfinance institution and housing program by targeting impoverished households in the town.

Keywords: Poverty, Income inequality, Logistic and quintile regression models, Medium-size town, Southern Ethiopia

*Correspondence: sisaydebebe2000@gmail.com

${ }^{1}$ College of Business and Economics, Department of Economics, Addis Ababa University, P.O.Box 5563, Addis Ababa, Ethiopia

Full list of author information is available at the end of the article

\section{Background}

Since 1991, the Ethiopia government gave great emphasis on poverty reduction and aspires to ensure food security by maintaining stable income inequality in its five-year development plans over the last years [1-4]. Despite such policies focus a considerable number of its people are poor, food insecure, and widening of income inequality

c) The Author(s) 2020. This article is licensed under a Creative Commons Attribution 4.0 International License, which permits use, sharing, adaptation, distribution and reproduction in any medium or format, as long as you give appropriate credit to the original author(s) and the source, provide a link to the Creative Commons licence, and indicate if changes were made. The images or other third party material in this article are included in the article's Creative Commons licence, unless indicated otherwise in a credit line to the material. If material is not included in the article's Creative Commons licence and your intended use is not permitted by statutory regulation or exceeds the permitted use, you will need to obtain permission directly from the copyright holder. To view a copy of this licence, visit http://creativeco mmons.org/licenses/by/4.0/. The Creative Commons Public Domain Dedication waiver (http://creativecommons.org/publicdomain/ zero/1.0/) applies to the data made available in this article, unless otherwise stated in a credit line to the data. 
over time. Therefore, still reducing the levels of poverty, achieving moderate income inequality distribution, and ensuring the food security status of its people is the primary concern of the government.

The trends of poverty and income inequality between $1999 / 2000$ to $2015 / 2016$ periods based on national representative panel survey estimation result by [5] explain that the situation of poverty has been improving in urban than rural areas, but with considerable variation across the different regions of Ethiopia. The decline of poverty with all measures was observed between 1995 to $2015 / 2016$ with head count index 33.2 in $1995 / 1996$ declined to 14.8 in $2015 / 2016$, with poverty gap index 9.9 in 1995 to 3.7 in 2015/2016 and with poverty severity index 4.1 in 1995 to 1.4 in 2015/2016. Similarly, the level of poverty is substantially declining in urban than rural with headcount indices from 36.9 in 1999/2000 to 35.1 in 2004/2005, further declined from 30.4 in 2010/2011 to 14.3 in $2015 / 2016$; while rural poverty declined with headcount indices from 45.4 in $1999 / 2000$ to 39.3 in $2004 / 2005$ and further declined from 30.4 in 2010/2011 to 25.6 in 2015/2016. Despite such tremendous decline of poverty over the last years, still a worrying concern as significant proportion of the population remains poor in rural areas indirectly shows the prevalence of food insecurity in rural areas. On the other hand, the trends of income inequality measured by Gini coefficient shows increasing trend from 0.29 in 1995 to 0.3 in 2010/2011 and rising to 0.33 in 2015/2016 with more inequality in urban than rural areas of Ethiopia. The rising trend of income inequality over time is not only exacerbating food insecurity situation of the country [6], but also it might obscure the short- to long-term effects of the government welfare-oriented planning process.

Various empirical studies on poverty and income inequality were carried out in different parts of Ethiopia over the last years. Some of these studies were primarily done on poverty analysis at the national level and some regional areas of Ethiopia such studies are [7-15]. These studies used either income or expenditure to measure the level and distribution of poverty. Most other studies also measured income inequality using Gini-coefficient techniques in different parts of the country [16-18]. However, there are few studies that attempted to analyze both income inequality and poverty together at national or regional level such as [5, 19-21] and [22]. Such type of studies better indentifies common determinants and provides specific policy recommendations. Poverty and income inequality are highly interrelated concepts since income inequality weakens poverty reduction efforts of government via its indirect strong negative effect on economic growth and food insecurity [19, 23], and [6]. This study aims to address the research questions: what are the factors influencing poverty and income inequality? What are the effects of poverty and inequality on food insecurity status of households in the study area? This study, therefore, aims to measure the levels, identify determinants and analyze the effects of poverty and income inequality on food insecurity status of households in Sawla town of Southern Ethiopia.

\section{Research methodology \\ Description of the study area}

The study is carried out in Sawla town which a mediumsize town is found in Gofa zone of Southern Nation Nationalities and Peoples Region (SNNP) of southern Ethiopia. According to the Sawla municipality report, the town has a total surface area of 849.61 hectares and administratively sub-divided into 2 sub-cities and 10 kebeles (lowest administration unit). Figure 1 shows that the town is located at $6^{\circ} 17^{\prime} 59^{\prime \prime} \mathrm{N}, 36^{\circ} 52^{\prime} 48^{\prime \prime}$ E bordered by Demba Gofa Zuria district in all directions. According to [24] population census report the total population of the town is 54,801 from which 26,852 are male and the remaining 27,949 are female.

\section{Data sources and methods of collection}

Primary data were gathered from household head using structured questionnaire. The primary data constitute patient information related to the poverty and income inequality. The secondary data were also collected from relevant government office such as NPC, CSA and MoFED. In addition, Focus Group Discussion (FGD), Key Informant Interviews and personal observation were also collected to supplement the limitation of quantitative data.

\section{Sample design}

A total of 227 representative household head estimated using [25] sample size formula basing a 95\% confidence level, $\pm 5 \%$ precision and $18 \%$ probability of poor proportion estimation result by [12]. The resulting sample size is calculated using the formula in Eq. 1:

$$
n=\frac{Z^{2} P Q}{\varepsilon^{2}}=\frac{(1.96)^{2}(0.18)(0.82)}{(0.05)^{2}}=227,
$$

where $n$ is sample size, $Z$ distribution, $p$ probability of being poor in SNNP region, $q$ stand for probability of being non-poor in the region 0.82 and $e$ is marginal error.

Second-stage sampling techniques were applied to select representative household head: in the first stage, 5 Kebeles were randomly selected from 10 total Kebeles of the town. In second stage, 227 household head were selected randomly proportion to their total population size from each selected Kebele as shown in Table 1. 


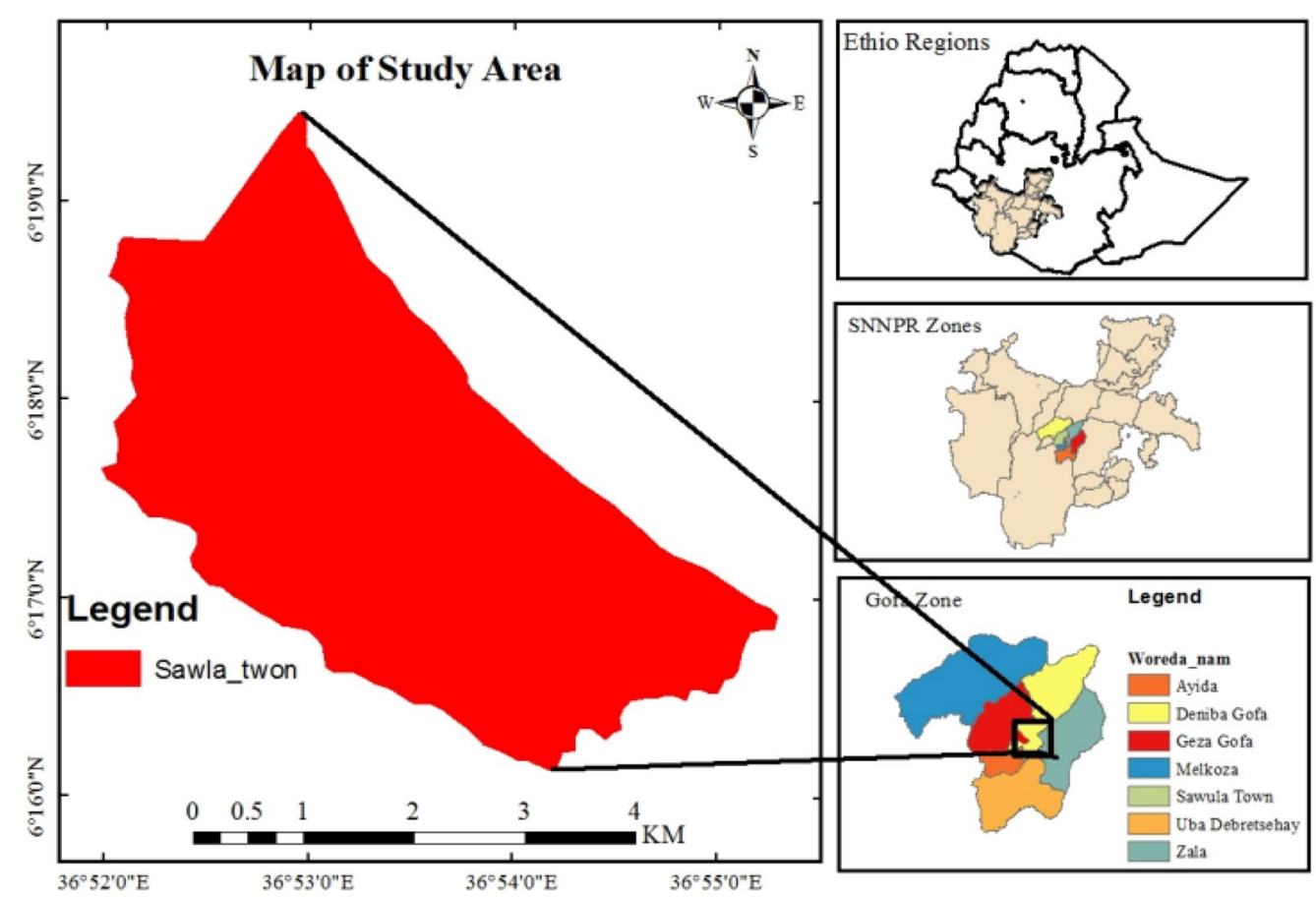

Fig. 1 Administrative map of Sawla town of Southern Ethiopia. Source: Sawla town municipality

Table 1 Sample selection with proportional allocation

\begin{tabular}{llccc}
\hline No. & Kebele & Total population & Proportional\% & Sample size \\
\hline 1 & Megenagna & 6450 & $23 \%$ & 52 \\
2 & Kust & 7960 & $28 \%$ & 63 \\
3 & Botire & 8775 & $31 \%$ & 70 \\
4 & Gurade & 3005 & $11 \%$ & 24 \\
5 & Yala & 2270 & $8 \%$ & 18 \\
& Total & 2,8460 & $100 \%$ & 227 \\
\hline
\end{tabular}

Sources: own computation

\section{Method of data analysis}

To analyze the data descriptive statistics, FGT (Foster Greer Thorbecke) indexes, Gini coefficient and econometric models (binary logistic and quintile regression models) were applied. The detailed descriptions of each technique are provided below.

\section{Poverty and food insecurity estimation techniques}

The most widely used method of estimating poverty line is the cost of basic needs (CBN) using the consumption expenditure approach since most people under-report their income than their expenditure [26]. In view of this, the study measures the real per capita consumption expenditure on caloric intake estimated both food and total poverty indices using the criterion set by $[13,27]$.
To estimate the food insecurity indices, a calorie intake of $2200 \mathrm{kcal}$ per day per adult food consumption as a cut-off line applied in the study [28] and [29]. Based on [27] and [26], the estimation of poverty indices was estimated using the widely applied method and estimates three measures: the share of the sampled household head whose consumption is below the poverty line or the share of sampled household head that cannot buy a basic basket of goods (headcount index), depth of poverty shows how far households are far from poverty line (poverty gap index), and severity of poverty measures the distribution of consumption expenditure per adult equivalent among the poor or inequality among the poor (squared poverty gap) [30]. The statistical formula of FGT that translates well-being indicators into poverty indices estimated using the following equation:

$$
P_{\alpha}(Z, Y)=\frac{1}{n} \sum_{i=1}^{q}\left[\frac{Z-Y_{i}}{Z}\right]^{\alpha},
$$

where $Z$ is poverty indices, $Y$ is the measure of actual consumption expenditure in adult equivalent for basic basket of goods and services, $n$ is sample household head, $q$ is the number of household head (usually those below the poverty line, $\alpha$ is poverty parameter (assumes $0,1$ and 2$)$ and $P_{\alpha}$ is the poverty index. Head count index $\left(P_{0}\right)$, poverty gap index $\left(P_{1}\right)$ and severity index $\left(P_{2}\right)$. FGT poverty indices are also mostly applied and estimated the 
status of poverty in their respective studies $[10,12,15$, 20, 22].

Similary to [28] and [29], the food security composite indices estimated using [30] estimation techniques. FGT measures the three measures of food insecurity: the share of food-insecure household head (headcount index), food insecurity gap (food insecurity gap index) and the distribution of calorie intake of 2200 kilocalorie per adult per day (severity of food insecurity index). The statistical formula of FGT that translates indicators of food security indices estimated using the following equation:

$$
F_{\alpha}(C, Y)=\frac{1}{n} \sum_{i=1}^{q}\left[\frac{Z-Y_{i}}{Z}\right]^{\alpha},
$$

where $F$ is food insecurity indices, $Y$ is the measure of per adult equivalent food kilocalorie intake of the sampled household head, $\mathrm{n}$ is sample household head, $q$ is the number of food-insecure household head, $\alpha$ is food insecurity parameter (assumes 0,1 and 2) and $P_{\alpha}$ is the food insecurity index. Food insecurity head count index $\left(P_{0}\right)$, food insecurity gap index $\left(P_{1}\right)$ and food insecurity severity index $\left(P_{2}\right)$. FGT food insecurity indices are also mostly applied and estimated the food insecurity indices using similar method in Ethiopia [31] and [32].

\section{Income inequality estimation techniques}

To measure the extent of income inequality Gini coefficient was applied in the study area. The Gini coefficient index value ranges from 0 to 1 with a value equal to 1 indicating there is a considerably high degree of income inequality or unfair distribution of income among the society. The estimation of the Gini coefficient index was estimated based on a ratio of the areas on the Lorenz curve. Gini coefficient measured the area between the perfect equality line and the Lorenz curve. The estimation of the Gini coefficient specified using [26]:

$$
\operatorname{Gini}(G C)=1-\sum_{i=1}^{N}\left(X_{i}-X_{i-1}\right)\left(Y_{i}+Y_{i-1}\right),
$$

where $X_{\mathrm{i}}$ is the cumulative percentage of the population, $Y_{\mathrm{i}}$ is the value of the cumulative percentage of income per adult equivalent and $\mathrm{n}$ is the sample size. Most previous studies such as $[5,16]$, and [22] also used Gini coefficient to measure the level of income inequality in their respective studies.

\section{Analytical methods}

Binary logistic regression model is used to determine the determinant of poverty while the quantile regression model used to identify determinants of income inequality.

\section{Binary logistic model}

Binary logistic regression model was used to estimate the determinants of poverty. The model is best suited when the dependent variable assumes dummy variable [33]. In this study, the dependent variable is being poor or non-poor household head which was classified using the head count index $\left(\mathrm{P}_{0}\right)$ of FGT indices. Based on [33], the binary logit model is specified as:

$$
P\left(Y_{t}=1 \mid X \mathrm{i}\right)=\frac{e^{Y i}}{1+e^{Y i}} .
$$

If we took ratio of probability of being poor divided probability being non-poor gives us odds ratio:

$$
\frac{P}{1-P}=\frac{\frac{e^{Y i}}{1+e^{Y i}}}{\frac{1}{1+e^{Y i}}}=e^{Y i} .
$$

Furthermore, taking natural $\log$ for both sides to the above equation and the resulting equation is called logit:

$$
\ln \left(\frac{P}{1-P}\right)=\ln e^{Y_{i}}=Y_{i}=\beta_{i} X_{i}+\varepsilon_{i}
$$

where $Y_{\mathrm{i}}$ is the status of household $\mathrm{i}$ which assumes two dummy variable ( 1 if the household is poor, 0 if not), $X_{\mathrm{i}}$ is the set of explanatory variables and $\varepsilon_{i}$ is the error term. The definition of explanatory variables, measurement and their expected hypotheses are explained in Table 2.

\section{Quintile regression model}

The classical quantile regression is an extension of multiple regression model, first introduced by [34] which predicts explanatory variables relates at different points of the dependent variables and has a comparative advantage when errors are highly non-normal and hence automatically adjusted the non-normal errors and outliers data sets which are most likely in income inequality analysis. In addition, the method allows the richer for easy characterization of the data that allows the impact of a covariate on the entire distribution of $\mathrm{Y}$ which is not merely its conditional mean. Besides, it precisely depicts the stochastic associations between random variables. The quantile regression model was applied by most previous income inequality analysis studies such as [16, 18, 20,22]. Based on [34] and [18], the quantile regression model specified as:

$$
Q_{\tau} \ln \left(Y_{i} / X_{i}\right)=x_{i}^{\prime} \beta_{\tau}+\varepsilon_{i, \tau}
$$

where $Q_{\tau} \ln \left(Y_{i} / X_{i}\right)$ is suggesting to estimate the $\log$ of total income per adult equivalent model $\tau$ th quantile $Q_{\tau}$ 
Table 2 Definition of variables, measurement, descriptive statistics and hypotheses

\begin{tabular}{|c|c|c|c|c|}
\hline \multirow[t]{2}{*}{ Variables } & \multirow[t]{2}{*}{ Measurements } & \multirow{2}{*}{$\begin{array}{l}\text { Descriptive statistics } \\
\text { Frequency (\%)/mean (St. Dev.) }\end{array}$} & \multicolumn{2}{|c|}{ Hypotheses } \\
\hline & & & Poverty & $\begin{array}{l}\text { Income } \\
\text { inequality }\end{array}$ \\
\hline Sex & Male/female & $155(68.7)$ & - & - \\
\hline Age & Years & $43.40(12.24)$ & \pm & \pm \\
\hline Education & Years & $10.05(5.08)$ & - & + \\
\hline Family size & Adult equivalent & $5.26(2.26)$ & + & - \\
\hline \multirow[t]{4}{*}{ Marital status } & 1. Married & $177(77.9)$ & \pm & \\
\hline & 2. Single & $8(3.52)$ & & \\
\hline & 3. Widowed & $29(12.78)$ & & \\
\hline & 4. Divorced & $13(5.73)$ & & \\
\hline Energy source-electricity & Yes/no & $180(79.30)$ & - & + \\
\hline \multirow[t]{4}{*}{ Main occupation } & 1. Unemployed & $25(11)$ & \pm & \pm \\
\hline & 2. Agriculture & $43(19)$ & & \\
\hline & 3. Trade & $66(29)$ & & \\
\hline & 4. Wage worker & $93(41)$ & & \\
\hline Remittance & Yearly in birr & $61.25(249.06)$ & - & + \\
\hline Savings & Monthly in birr & $740.98(613.7)$ & - & + \\
\hline Access to credit & Yes/no & $211(92.95)$ & - & + \\
\hline House ownership & Yes/no & $178(78.41)$ & - & + \\
\hline Water supply & Yes/no & $167(73.57)$ & - & - \\
\hline Health status & Sick family member/not & $10(4.41)$ & & - \\
\hline Migration status & Migrant family member/not & $45(19.82)$ & & \pm \\
\hline
\end{tabular}

Source: Own survey, 2019

of the distribution of dependent variable $(Y)$ conditional on the value of $X$. of interest. The description of explanatory variables, measurement and their hypotheses is given in Table 2 .

$$
Q \ln \left(Y_{i} / X_{i}\right)=\sum_{i: y i \geq x^{\prime} \beta}^{N} q\left|y i-X^{\prime}{ }_{i} \beta q\right|+\sum_{i: y i \leq x^{\prime} \beta}^{N}(1-q)\left|i-X^{\prime}{ }_{i} \beta q\right|
$$

$$
=\sum_{i=1}^{n}\left[(1-q)(y i) \leq X_{i}^{\prime} \beta\right]\left(y i-X_{i}^{\prime} \beta\right),
$$

where $Y_{\mathrm{i}}$ is the income per adult equivalent of the $i$ th household, represents a column vector of realizations on $k$ explanatory variables, and $\beta$ is the column vector corresponding to unknown parameters $0 \leq q \geq 1$ is quantile

\section{Result and discussion \\ Measurement of poverty and its determinants Poverty indices result}

The estimation of poverty line estimated using the [13] and [35] poverty classification benchmark criterion: consumption expenditure less than 400 and 586 birrs (Ethiopian currency) per month are classified as poor in

\begin{tabular}{|c|c|c|c|c|c|c|c|}
\hline \multirow[t]{2}{*}{ Groups } & \multirow[t]{2}{*}{ Freq } & \multirow[t]{2}{*}{$\%$} & \multicolumn{5}{|c|}{ Consumption expenditure per adult per month } \\
\hline & & & Mean & Min & Max & St. Dev & t-statistics \\
\hline Poor & 78 & 34.4 & 376.72 & 49.78 & 574.40 & 116.85 & $3.61^{* * *}$ \\
\hline Non-poor & 149 & 65.6 & 1850.60 & 586.49 & 16451.33 & 844.8 & \\
\hline Total & 227 & 100 & 1344.16 & 49.78 & 16451.33 & 825.27 & \\
\hline
\end{tabular}

Table 3 Summary of consumption expenditure between poor and non-poor

Source: own survey (2019)

${ }^{*}, *$ and $^{* * *}$ are statistical significance level at $1 \%, 5 \% \& 10 \%$, respectively 
food and total poverty, respectively. The result in Table 3 shows the mean expenditure of the poor was $376.72 \mathrm{birr}$ while the non-poor was 1850.59 birr per adult equivalent per month, respectively. Further, there is statistically significant mean consumption expenditure per adult per month differences between the poor and non-poor household head at $1 \%$ significance level.

Table 3 shows $34 \%$ headcount, 11\% gap and 5.6\% severity of total poverty, while $43 \%$ headcount, $16 \%$ gap and $8 \%$ severity of food poverty in the study area. The result implies that the poverty gap index indicates that the minimum amount of money to lift up all households to the poverty line. The result shows every poor household on average needs to get $564.5(0.11 * 586)$ birr per adult per month to be not poor. Concerning the poverty gap, a lower value indicates that most of the poor bunched around the poverty line. A higher value of the poverty gap indicates the terrible condition of the poor. In addition, the extents of food poverty with all measures are slightly bigger than total poverty due to the fact that the majority portion of the poor household disposable income allocated for purchasing food items. The results of food and total poverty with all measures in the study area are higher than the national average of medium-size urban areas of Ethiopia [35]. The result suggested that poverty in medium-size towns is largely triggered by a lack of sufficient food at the household level (Table 4).

\section{Determinants of poverty}

In Table 5, the likelihood ratio Chi-square value of 167.50 is statistically significant at $1 \%$ level of significant suggesting that the goodness of the model result. Out of hypothesized variables such six, family size and being divorced from the household head was increasing the probability of being poor. On the other hand, the level of education, trade as a main occupation, the level of savings and ownership of the house was decreasing the probability of being poor in the study are.

Educated household head negatively affected the probability of being poor and statistically significant at $1 \%$ level of significance. Keeping all other things constant, increasing the level of the household head by 1 year will reduce the probability of being poor by $84 \%$. The negative result could be justified due to the

Table 4 Poverty incidence, depth, and severity of poverty

\begin{tabular}{llll}
\hline & $\begin{array}{l}\text { Headcount }\left(\mathbf{P}_{\mathbf{0}}\right) \\
\text { (incidence) }(\mathbf{S t .} \\
\text { Dev.) }\end{array}$ & $\begin{array}{l}\text { Poverty-gap } \\
\left(\mathbf{P}_{\mathbf{1}}\right)(\text { depth) } \\
\mathbf{D e v})\end{array}$ & $\begin{array}{l}\text { Poverty-severity } \\
\left(\mathbf{P}_{\mathbf{2}}\right) \\
(\text { severity) }(\text { St. } \\
\text { Dev.) }\end{array}$ \\
\hline $\begin{array}{l}\text { Food poverty } \\
\text { Total Poverty }\end{array}$ & $0.427(0.033)$ & $0.1576(0.016)$ & $0.08(0.01)$ \\
\hline
\end{tabular}

Table 5 Binary logistic model result

\begin{tabular}{|c|c|c|c|c|}
\hline Variables & Coef & Std. Err & Z-score & Odd ratio \\
\hline Sex & -0.29 & 0.539 & -0.53 & 0.75 \\
\hline Age-square & 0.001 & 0.000 & 0.56 & 1.00 \\
\hline Education & -0.18 & 0.061 & $-2.90^{* * *}$ & 0.84 \\
\hline Martial single & -0.07 & 1.049 & -0.07 & 0.93 \\
\hline Widowed & 0.47 & 0.805 & 0.59 & 1.60 \\
\hline Divorced & 3.77 & 1.668 & $2.26^{* *}$ & 43.57 \\
\hline Family size & 0.44 & 0.146 & $2.98^{* * *}$ & 1.55 \\
\hline Savings & 0.001 & 0.001 & $-2.55^{* *}$ & 1.32 \\
\hline \multicolumn{5}{|l|}{ Occupation } \\
\hline Unemployed & 0.87 & 0.855 & 1.01 & 2.38 \\
\hline Agriculture & -0.19 & 0.692 & -0.27 & 0.83 \\
\hline Trader & -3.95 & 1.165 & $-3.39^{* * *}$ & 0.22 \\
\hline Wage worker & -0.90 & 1.149 & -0.78 & 0.41 \\
\hline Remittance & 0.001 & 0.002 & -1.00 & 1.00 \\
\hline Access to credit & 0.53 & 0.864 & 0.62 & 1.70 \\
\hline House ownership & -1.68 & 0.543 & $-3.10^{* * *}$ & 0.19 \\
\hline Electric & -0.40 & 0.641 & -0.62 & 0.67 \\
\hline Tap water & 0.07 & 0.548 & 0.12 & 1.07 \\
\hline _Cons & 0.16 & 1.601 & 0.10 & 1.17 \\
\hline $\operatorname{LRChi}{ }^{2}(17)$ & $167.50^{* * *}$ & & & \\
\hline Log likelihood & -56.49 & & & \\
\hline Pseudo-R ${ }^{2}$ & 0.58 & & & \\
\hline
\end{tabular}

Source: model result (2019)

fact that education has widened the competitiveness of employment informal sectors and enhance the higher income earning potential of the household head. The result is also confirmed by [9] and [12] in their respective studies.

As per the prior expectation, households with divorced heads as compared to married households head affected positively the probability of being poor and statistically significant at a $5 \%$ significance level. The result implies that the probability of being poor for a divorced headed household is $57 \%$ times higher than the married household head, keeping all other variables constant. Since divorce would result in the division of family members, it increases the probability of being poor. Similarly, the divorced and widowed households' heads resulted in a higher probability of falling into poverty than the married and single household heads [11]. This result is also confirmed by [20] and [36] in their respective studies.

Family size affected positively affected the probability of being poor and statistically significant at $1 \%$ of the level of significance. This implies that when there is large family size, there exists a higher dependence ratio and less available resources per individual. As a member of family size increases by one, the probability of being 
poor of the household head increases by $55 \%$. This result is consistent with other studies [9, 10, 12, 20] and [36].

Amount of savings affected negatively the probability of being poor and statistically significant at a $6 \%$ significance level. The result implies as the amount of savings increased by one birr the probability of being poor decreases $32 \%$. The negative result could be justified due to the fact that that amount of savings would facilitate credit access to start a business and could be also used to coping with short-term market shocks. Similarly, [12, 37] found similar fining in his study.

The result revealed that households who participate in business activities (traders) as the main occupation as compared to those who are unemployed have negatively and significantly affected the probability of being poor at $1 \%$ level of significance. The result implies that the probability of being poor for traders headed household is $22 \%$ times higher than the unemployed household head, keeping all other variables constant. The result might be due to the fact that participating in small enterprises helps as a means of earning additional income and hence contribute to the reduction of poverty.

House ownership has negatively affected the probability of being poor and statistically significant at 5\% level of significance. The odds ratio in favor of house owners implies that the probability of being poor for house owners is $19 \%$ lower than non-owners are. The possible explanation of the result implies that households who have their own house reduces the cost of house rent and hence they divert the house rent income which is a significant portion of the total expenditure to meet other basic needs. This finding is consistent with [14].

\section{Measurement of income inequality, food insecurity and its determinants Measurement of income inequality}

The result of Fig. 2 shows the Lorenz curve for Sawla town and sampled areas of the town. X-axis and Y-axis represent cumulative percent age of households and income ordered from the poorest to rich, respectively. The distribution of total household income shows there are considerable income inequality disparities across sample areas of the town.

The result of Gini coefficient in Table 6 shows the extent of income inequality estimated found to be 0.447 which indicates that there is considerable unequal distribution of income in the town. Moreover, the results of Gini coefficient in the sampled areas of the town show a considerable variation across with highest income inequality 0.5895 observed in Megenagna and lowest value income inequality 0.2639 in Yala kebele of the town. The result of Gini coefficient in the town is higher than the

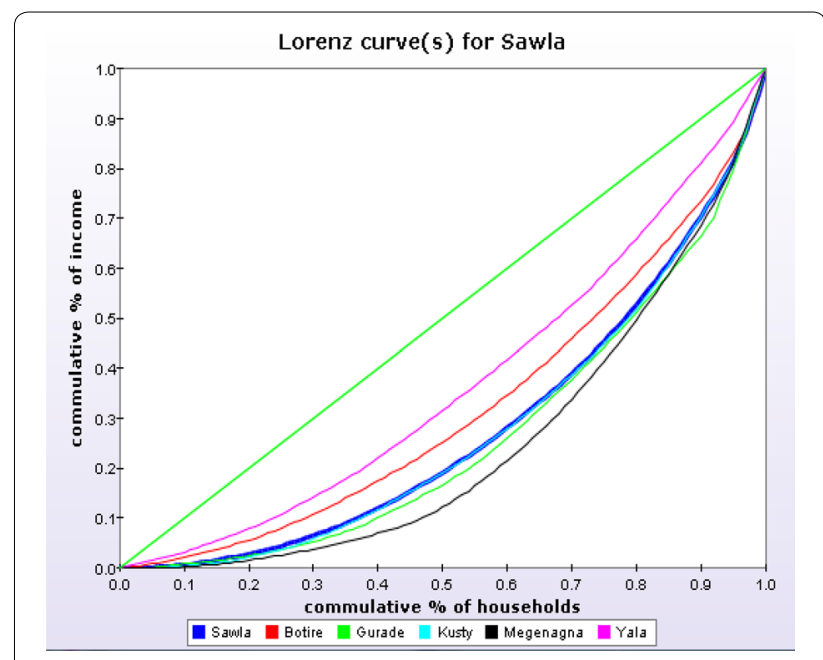

Fig. 2 Lorenz curve graph for study area. Source: own survey (2019)

Table 6 Gini coefficient result in the study area

\begin{tabular}{ll}
\hline Kebele (study area) & Gini coefficient \\
\hline Botire & 0.5895 \\
Gurade & 0.3043 \\
Kust & 0.4180 \\
Megenagna & 0.4643 \\
Yala & 0.4708 \\
Total & 0.447 \\
\hline
\end{tabular}

Sources: own survey (2019)

national average value of 0.38 in 2015/2016 of Ethiopian urban areas [35].

\section{Determinate of income inequality}

Quantile model is employed to analyze the determinate of the household's income inequality. The result shows that 11 variables were found to have statistically significant effect on income inequality. The variables are agesquare, education of household, house ownership, wage worker, access to credit, electric, savings, remittance, family size in adult equivalent, health, and trade (business participation). As shown in Table 7, quantile regression is a good fit model with significant value of F-statistics and pseudo- $R^{2}$ ranging between 0.3559 to 0.4487 indicating the model fits well and adequately represents the empirical data.

Quantile model regression coefficient used to indicate direction and magnitude of the impact of the explanatory variables on the dependent variable (income per adult equivalent). Quantile regression result shows agesquare-associated higher income per adult equivalent and significant at median and 75th quintiles. The variable "age square" stands for the impact of age at a very 


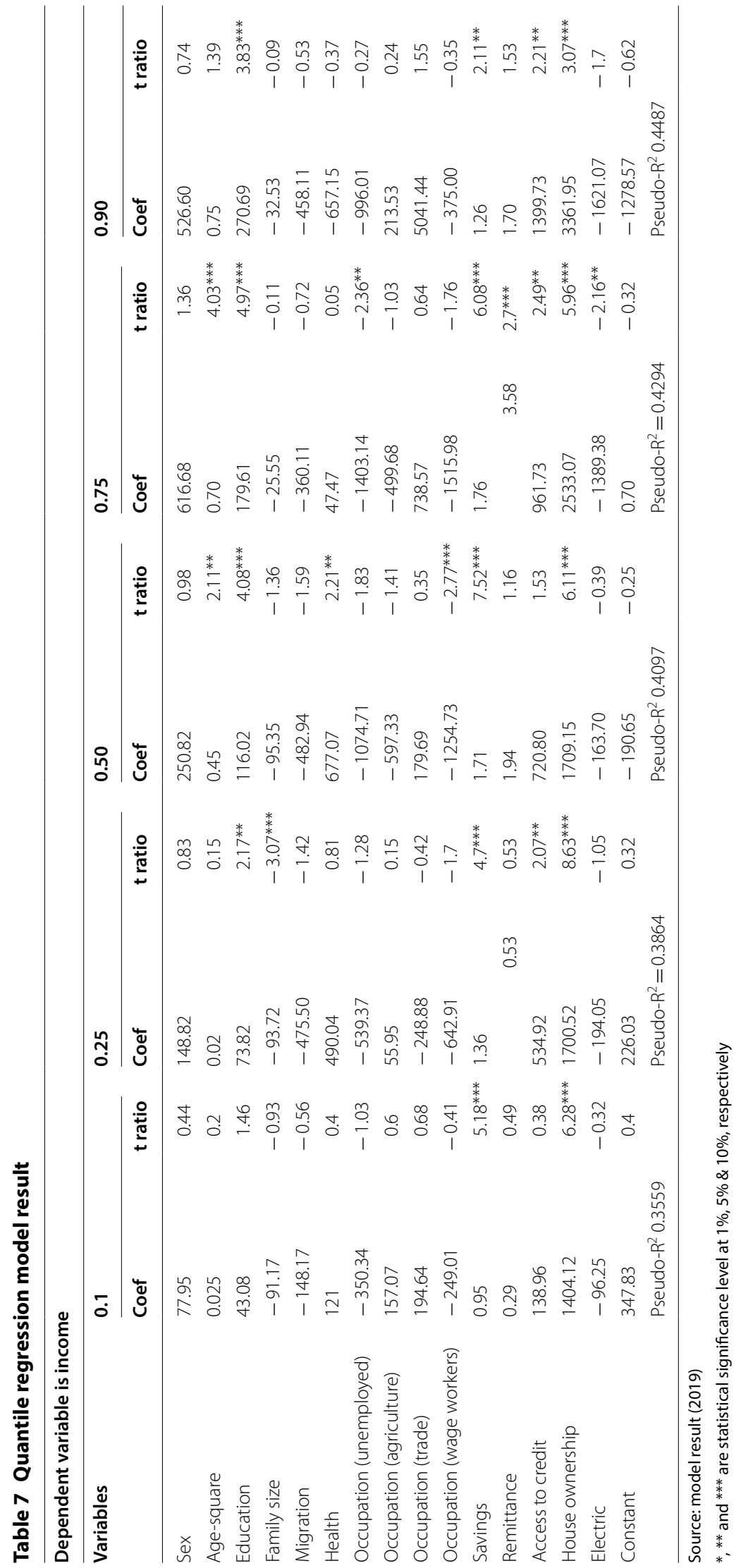


higher level and this is also in agreement with the human capital theory which says income increases with age but at a decreasing rate. The possible explanation for this is that at a very higher age accumulation of wealth increases and this result in high income per adult equivalent. This result is consistent with the results of previous studies taken by [16] and [38].

As expected, education level of household head influenced positively income per adult equivalent across quintiles and significantly at 25th, 50th 75th and 90th quintiles). Other things remain constant, accruing of one additional year of schooling will results in increment income per adult equivalent by birr 73, 106, 179, 270 per month at 25th, 50th 75 th and 90th quintiles, respectively. In other words, the education of household head increases with income per adult equivalent (higher quintiles). This result shows that educated households head have relatively better knowledge and highly commutative for better jobs, consequently have a higher income than households with a lower levels of education. The evidence obtained is in accordance with earlier studies which have shown individuals with higher levels of education are more likely to hold jobs that involve performing more complex tasks and that have better career perspectives and retirement plans. This result is also consistent with a study conducted by [9, 16, 39], and [40].

In contrast, family size measures in adult equivalent the quintile regression result show negative association across quintiles and only significant at 25th quintiles income distribution. Large families usually have lower income per adult equivalent which implies more family size is related to more working-age members per family and thereby increases the probability of earning income. This finding is in line with [16] and [40] in their respective studies.

As far as sources of income for household heads are concerned, households whose main source of income is from wage worker were negatively associated with the income per adult equivalent across quintiles and only significant at 50th quantiles. Likewise, as to prior expectations, the coefficient of the unemployed household head indicates that there exists a negative relationship between unemployment of household heads and income per adult equivalent of households. But the negative relationship is significant only at 75 th quintiles. Keeping other variables constant, for households with unemployed heads have lower income per adult equivalent by factor 1403 as compared to government and private sectors employees. This result is in line with studies conducted by $[9,20,40]$, and [5].

Savings is another economic factor that positively and significantly affected the income level of household at 10 th, 25th, 50th, 75th, and 90th quantiles. This might be because savings is an additional source of funds for business expansion and other activities. Similarly, access to credit service shows positive effect across quintiles, but the effect is significant only at 25th, 75th, and 90th quintiles. The possible explanation for this is that households who save part of their income have the advantage to get credit, own business and have an asset. This result is in line with other studies in their respective studies such as [20].

Remittance is another economic factor that has influence on the income level of households positively at all quintiles and only significantly influences at 75th quintiles. Other things remaining constant, 1-birr increase in remittances will results in 3.4ETB increases in income per adult equivalent per month at 75 th quintiles. Since remittances are a result of additional income that directly led to the higher income of households, this study is in line with [20] and [5]. Moreover, health status measured by sick members of households showed a negative relationship with income per adult equivalent in all quintiles, but only significant at the median quintile.

House ownership has positively and statistically significantly associated with income per adult equivalent at all quintiles. Other things remaining constant, house owners have a higher level of income than non-owners by Ethiopian Birr (currency) 1404, 1700, 1709, 2533 and 3361 at 10 th, 25 th, 50 th, 75 th and 90th quintiles, respectively. House-owner households have higher income per adult equivalent for higher quintiles as compared to non-owners. The possible explanation for this is that high housing tenure resulted in a high cost of living. Further, most urban poor were living in the public houses are characterized by low income, unemployment, and high composition of widowers and elders. This study is also in line with studies conducted by [16]. However, other researchers found ownership of the house does not imply that households are wealthy [40].

\section{Poverty, income inequality and its effect on household's food insecurity \\ Food insecurity indices result}

In Table 8 , the finding of the study on food insecurity indices indicated that the incidence of food insecurity

Table 8 Incidence, depth, and severity of food insecurity indices

\begin{tabular}{llll}
\hline & $\begin{array}{l}\text { Headcount }\left(F_{0}\right) \\
\text { (incidence) }(s t . \\
\text { dev.) }\end{array}$ & $\begin{array}{l}\text { Food insecurity } \\
\text { gap }\left(F_{1}\right)(\text { depth) } \\
(\text { st. dev. })\end{array}$ & $\begin{array}{l}\text { Severity of food } \\
\text { insecurity }\left(F_{2}\right) \\
\text { (severity) }(S t . \\
\text { Dev.) }\end{array}$ \\
\hline Food insecurity & $0.496(0.036)$ & $0.2076(0.019)$ & $0.13(0.08)$ \\
\hline
\end{tabular}

Source: model result (2019) 
was $49.6 \%$ indicating that close to half of the total sampled households faced food insecurity, unable to get the minimum life-sustaining calorie intake in the study area. The depth of food insecurity shows that each food-insecure household needed to be supplied $20.76 \%$ of daily caloric requirement to escape from food insecurity. The average extent of the severity of food insecurity index shows on average 13\% inequality among food-insecure households in the study area. The result of food insecurity indices in the town is similar to that of other medium-size towns of western Ethiopia [32].

\section{Poverty and income inequality effects on food insecurity}

The result of comparison between food secure and insecure households with the poverty indices shows that, the proportion of food poor households is significantly higher among food-insecure households (45.86\%) than food-secure households (38.52\%). Similarly, food-insecure households have significantly higher proportion of households far from the food poverty line (18.99\%) than food-secure households (11.21\%). They also have significantly more proportion of total poor households (38.24\%) than non-adopter households (28.48\%) suggesting that the incidence and depth of poverty exacerbate food insecurity status of the households in the study area (Table 9).

There are also significant differences in terms of the distribution of income between food-secure and insecure households. Food-insecure households have significantly larger income inequality in Gini coefficient (0.4785) than food-secure households (0.3911). The result suggests that income inequality worsens the food insecurity status of households in the study area.

\section{Conclusions}

The food poverty line and poverty line (total poverty line) have been calculated to be 400 and 586 birrs per adult per month, respectively. From the total household head 34\% are living below the poverty line ( 529 birr) with a poverty gap index (0.11) and poverty severity index (0.058).With $42 \%$ food poverty headcount index, $15 \%$ poverty gap, and $8 \%$ severity indexes $49.6 \%$ of sample households are food insecure with $20.7 \%$ depth and $13 \%$ severity indexes of food insecurity. On the other hand, the result of 0.45 Gini coefficient result being higher than the national average result for medium-size town with considerable variation across sampled kebeles warrants the attention of the policymakers. The result of the binary logit model attested that level of education, family size, trade as a main occupation, level of savings, house ownership, and being divorce determined the status of poverty in the study area. While the result of the quantile regression model shows that age, level of education, ownership of house, being a wage worker, access to credit, use of electricity as energy source, the level of savings, remittance, family size, health status, and being trader as main occupation are the factors contributing to income ineqaulity. Moreover, the determinants of both poverty and income inequality overlap substantially because the same variable plays a simultaneous role in the reduction of poverty and income inequality in the study area. Therefore, the higher incidences of poverty, high-income inequality and its adverse effect on food insecurity status of household's calls for strengthening welfare-oriented strategies such as productive safety net and emergency relief aid programs. Besides the goverment should strengthen the implementation of poverty reduction programs via providing greater access to women for intra-household

Table 9 Poverty, income inequality and their effect on household's food security status

\begin{tabular}{|c|c|c|c|}
\hline & Food secure $(n=114) \%$ or mean & Food insecure $(n=113) \%$ or mean & $\chi^{2}$ or t-test (Std. Error) \\
\hline \multicolumn{4}{|l|}{ Food poverty } \\
\hline Headcount (Incidence) & 38.52 & 45.86 & $-7.34^{* *}(0.033)$ \\
\hline Gap (depth) & 11.21 & 18.99 & $-7.78^{*}(0.047)$ \\
\hline Severity & 0.9 & 0.07 & $0.97(0.068)$ \\
\hline \multicolumn{4}{|l|}{ Total poverty } \\
\hline Headcount (incidence) & 29.48 & 38.24 & $-9.24^{* *}(0.079)$ \\
\hline Gap (depth) & 12.06 & 11.1 & $0.96(0.065)$ \\
\hline Severity & 6.21 & 5.24 & $0.97(0.068)$ \\
\hline \multicolumn{4}{|l|}{ Income inequality } \\
\hline Gini coefficient & {$[0.3911]$} & {$[0.4785] 0.4472$} & $-0.09^{b}(0.306)$ \\
\hline
\end{tabular}

1. Variable in parentheses is mean

2. ${ }^{* * *},{ }^{* *}$ and ${ }^{*}$ indicate the level of significance at 1,5 and 10 percent, respectively

Source: model result (2019) 
resources, promoting the use of family planning methods, encouraging participation of diversified business activities, strengthening the existing microfinance and formal financial institutions, increasing accessibility of formal education, providing affordable house development program for low-income earners particularly to vulnerable sections of the society (i.e., the divorced and widowed household head) in the town.

\begin{abstract}
Abbreviations
CBN: Cost of basic needs; CSA: Central Statistical Authority; FDRE: Federal Democratic Republic of Ethiopia; FGT: Foster Greer Thorbecke; MoFED: Ministry of Finance and Economic Development; NPC: National Planning Commission; PSNP: Productive Safety Net Program; SNNP: Southern Nation Nationalities and People Region; WBI: World Bank Institute.
\end{abstract}

\section{Acknowledgements}

We would like to extend our deep heartfelt gratitude to Arba Minch University for providing financial support and those who have helped in all courses in the research process

\section{Authors' contributions}

The first author led the overall research process and revised all parts of the manuscript including abstract, introduction, econometrics model specification and interpretation of the manuscript preparation. The second author participated in data collection and drafting of the preliminary result of the manuscript. Both authors read and approved the final manuscript.

\section{Funding}

Not applicable.

\section{Availability of data and materials}

The datasets used and/or analyzed in the study will be available from the authors on reasonable request.

\section{Ethical approval and consent to participate}

Prior to data collection, the authors requested an official support letter from the university that explains the overall purpose of the study to all concerned district offices, and then the researcher gets the consent of all households for supplying the required data for the study. The data obtained from respondents were kept confidential and used for academic purposes only. The primary data obtained from each respondent were kept confidential and agreed with the respondents to use for academic propose only. Finally, all participants including survey enumerators, supervisors, and key informants were provided adequate training for survey administration.

\section{Consent for publication}

Not applicable.

\section{Competing interests}

We declare that we do not have competing interests.

\section{Author details}

${ }^{1}$ College of Business and Economics, Department of Economics, Addis Ababa University, P.O.Box 5563, Addis Ababa, Ethiopia. ${ }^{2}$ College of Business and Economics, Department of Economics, Arba Minch University, P.O.Box 21, Arba Minch, Ethiopia.

Received: 25 February 2020 Accepted: 22 September 2020

Published online: 16 December 2020

\section{References}

1. MoFED. Sustainable development and poverty reduction program. Addis Ababa, Ethiopia. 2002
2. MoFED. A plan for accelerated and sustained development to end poverty. Federal Democratic Republic of Ethiopia, Building on progress: Addis Ababa, Ethiopia. 2006.

3. MoFED. Growth and Transformation Plan (GTP) 2010/11-2014/15. Addis Ababa, Ethiopia. 2010.

4. MoFED. Development and poverty in Ethiopia 1995/96-2010/11. Addis Ababa: Ministry of Finance and Economic Development, (2014).

5. Tassew W, Mesele W. Poverty and inequality in Ethiopia, 1995/6-2015/15. In Cheru F, Craner C, Arkebe Q (ed), The Oxford Handbook of THE ETHIOPIAN ECONOMY, United Kingdom: Oxford University Press. 2019.

6. Caracciolo F, Santeramo FG. Price trends and income inequalities: will Sub-Saharan Africa reduce the gap? African Dev Rev. 2013;25(1):42-54.

7. Abu G. The challenges and policies of poverty reduction in Ethiopia. Ethiopia e-J Res Innovation Foresight. 2013;5(1):94-117.

8. Adugna E, Sileshi E. Determinants of poverty in (agro-) pastoral societies of Southern Ethiopia. Livestock Res Rural Dev. 2013;25:2.

9. Beshir SB, Adem K, Belaineh L. Determinant of urban household poverty in Arsi Zone, Oromiya, Ethiopia. J Poverty Investment Dev. 2016;26:106-12.

10. Eshetu F. Determinants of rural Households' vulnerability to poverty in Chencha and Abaya districts, Southern Ethiopia (micro econometric analysis). J Econ Sustain Dev. 2016;07(01):41-56.

11. Jayamohan MK, Kitesa AT. Gender and poverty: an analysis of urban poverty in Ethiopia. Dev Stud Res. 2014;1(1):233-43. https://doi. org/10.1080/21665095.2014.917053.

12. Mohammed B. Measurement and determinants of urban poverty in case of SNNPR, Ethiopia. Int J Sci Res Publications. 2017;7(3):181-9.

13. NPC. 'Interim Report on 2015/16 Poverty Analysis Study', National Planning Commission (NPC), Addis Ababa. 2016.

14. Regassa, B, Regassa N. Housing and Poverty in Southern Ethiopia: examining Affordability of Condominium Houses in Hawassa City. Econ Sociol. 2015. 8(3):155-169. https://doi.org/10.14254/2071-789X.2015/8-3/12.

15. Sender J. Assessing poverty trends in Ethiopia, 1990-2015. In: Cheru F, Craner C, Arkebe Q, editors. The Oxford Handbook of THE ETHIOPIAN ECONOMY. United Kingdom, Oxford: Oxford University Press; 2019.

16. Fentaw A, Appa Rao CH. Determinants of income inequality in urban Ethiopia: a study of South Wollo Administrative Zone, Amhara National Regional State. Int J Appl Res. 2016;2(1):550-63.

17. Gobena E, Asefa B. Sources of income inequality among farm households in Ethiopia: using Gini coefficient approach. Am Based Res J. 2017;6(8):2304-7151.

18. Samuel T. The determinants of inequality and income gap between urban and rural areas in Cameroon: evidence from the ECAM3 household survey. Adv Econ Business. 2017;5(7):394-410. https://doi.org/10.13189/ aeb.2017.050703.

19. Alemayehu G, Abebe S, Weeks AJ. Growth, poverty and inequality in Ethiopia: which way for pro-poor growth? Addis Ababa. J Int Dev. 2009;21:947-70. https://doi.org/10.1002/jid.1517.

20. Araya M. Poverty and income inequality in urban areas: socio-economic analysis of households in Wukro wereda. Unpublished MA thesis. Mekelle University, Ethiopia, 2010.

21. Bigsten A, Bereket K, Abebe S, Mekonnen T. Growth and poverty reduction in Ethiopia: evidence from household panel surveys. World Dev. 2003;31(1):87-106.

22. Teka AM, Temesgen G, Fre Z. Status and determinants of poverty and income inequality in pastoral and agro-pastoral communities: household-based evidence from Afar regional state. Ethiopia World Dev Perspect. 2018;15(11):15-25. https://doi.org/10.1016/j.wdp.2019.100123.

23. Shimeles A. Growth, Poverty, and Distribution in Ethiopia. In: Cheru F, Craner C, Arkebe Q, editors. The Oxford Handbook of THE ETHIOPIAN ECONOMY, United Kingdom. Oxford: Oxford University Press; 2019.

24. CSA. Population Projection of Ethiopia for all regions at Wereda Level from 2014 to 2017. Ethiopia: Federal Democratic Republic of Ethiopia Central Statistical Authority, Addis Ababa. p. 2013.

25. Cochran WG. Sampling techniques. 2nd ed. New York: Wiley; 1963.

26. WBI. Introductory to poverty analysis: poverty manual, All, JH Revision. 2005.

27. NPC. 'Interim Report on 2010/11 Poverty Analysis Study', National Planning commission (NPC), Addis Ababa, (2010/11). 
28. FDRE. Food Security Strategy Food Security Assessment, Regional Overview Information Bulletin. Addis Ababa, Ethiopia, 1996.

29. Santeramo FG. Food security composite indices: implications for policy and practice. Dev Pract. 2015;25(4):594-600.

30. Foster J, Greer J, Thorbecke E. A class of decomposable poverty measures. Econometrica J Econ Soc. 1984. 761-766.

31. Endalew B, Muche M, Tadesse $S$. Assessment of food security situation in Ethiopia: a review. Asian J Agric Res. 2015;9:55-68.

32. Sani S, Kemaw B. Analysis of households food insecurity and its coping mechanisms in Western Ethiopia. Agric Food Econ. 2019;7:5. https://doi. org/10.1186/s40100-019-0124-x.

33. Gujarati ND. Essentials of econometrics. 4th ed. West Point: United states Military Academy; 2006.

34. Koenker R, Bassett G Jr. Regression quintiles. Econometerica. 1978;46(1):33-50.

35. NPC. Ethiopia's Progress Towards Eradicating Poverty: An Interim Report on 2015/16 poverty analysis study. Addis Ababa, (2017).
36. Bradshaw TK. Theories of poverty and anti-poverty programs in community development. Commun Dev. 2007;38:7-25.

37. Feldman G. Saving from poverty: a critical review of individual development accounts. Crit Soc Policy. 2017;38(3):181-200.

38. Crespo N, Simoes N, Diago AP. Determinant factors of income inequality? evidence from a Portuguese regions. Econ Bull. 2012;32(3):2056-64.

39. Jin Y, Xie Y. Social determinants of household wealth and income in urban China. Chin J Sociol. 2017;2(3):169-92. https://doi.org/10.1177/20571 50X17695689.

40. Rahman S. Factors influencing household income in poor urban slum settlements in Bangladesh. J Poverty Alleviation Int Dev. 2017;8(2):55-80.

\section{Publisher's Note}

Springer Nature remains neutral with regard to jurisdictional claims in published maps and institutional affiliations.
Ready to submit your research? Choose BMC and benefit from:

- fast, convenient online submission

- thorough peer review by experienced researchers in your field

- rapid publication on acceptance

- support for research data, including large and complex data types

- gold Open Access which fosters wider collaboration and increased citations

- maximum visibility for your research: over 100M website views per year

At BMC, research is always in progress.

Learn more biomedcentral.com/submissions 